\title{
Genetically Defined Inhibitory Neurons in the Mouse Spinal Cord Dorsal Horn: A Possible Source of Rhythmic Inhibition of Motoneurons during Fictive Locomotion
}

\author{
Jennifer M. Wilson, ${ }^{1,2}$ Evgueni Blagovechtchenski, ${ }^{1,2}$ and Robert M. Brownstone ${ }^{1,2,3}$ \\ ${ }^{1}$ Neuroscience Institute and Departments of ${ }^{2}$ Anatomy \& Neurobiology and ${ }^{3}$ Surgery (Neurosurgery), Dalhousie University, Halifax, Nova Scotia B3H 1X5, \\ Canada
}

To ensure alternation of flexor and extensor muscles during locomotion, the spinal locomotor network provides rhythmic inhibition to motoneurons. The source of this inhibition in mammals is incompletely defined. We have identified a population of GABAergic interneurons located in medial laminae V/VI that express green fluorescent protein (GFP) in glutamic acid decarboxylase-65::GFP transgenic mice. Immunohistochemical studies revealed GFP + terminals in apposition to motoneuronal somata, neurons in Clarke's column, and in laminae V/VI where they apposed GFP + interneurons, thus forming putative reciprocal connections. Whole-cell patch-clamp recordings from GFP + interneurons in spinal cord slices revealed a range of electrophysiological profiles, including sag and postinhibitory rebound potentials. Most neurons fired tonically in response to depolarizing current injection. Calcium transients demonstrated by two-photon excitation microscopy in the hemisected spinal cord were recorded in response to low-threshold dorsal root stimulation, indicating these neurons receive primary afferent input. Following a locomotor task, the number of GFP + neurons expressing Fos increased, indicating that these neurons are active during locomotion. During fictive locomotion induced in the hemisected spinal cord, two-photon excitation imaging demonstrated rhythmic calcium activity in these interneurons, which correlated with the termination of ventral root bursts. We suggest that these dorsomedial GABAergic interneurons are involved in spinal locomotor networks, and may provide direct rhythmic inhibitory input to motoneurons during locomotion.

\section{Introduction}

Inhibitory neurons in the spinal cord play fundamental roles in generating movement. During locomotor activity, inhibitory neurons are involved in flexor-extensor alternation (Nakayama et al., 2002), left-right coordination (Lanuza et al., 2004), and regulation of locomotor speed (Gosgnach et al., 2006). Furthermore, spinal motoneurons receive alternating excitatory and inhibitory input during locomotion (Jordan, 1983; Perret, 1983) from incompletely defined sources. Many populations of ventral inhibitory interneurons, including Ia inhibitory interneurons (IaINs) and Renshaw cells (RCs), derive from the V1 class of developing neurons and provide major inhibitory input to motoneurons (Alvarez et al., 2005). Early evidence suggested that IaINs play a role in motoneuronal inhibition during locomotion (Feldman and Orlovsky, 1975; McCrea et al., 1980; Pratt and

Received March 24, 2009; revised Nov. 10, 2009; accepted Nov. 12, 2009.

This work was supported by the Canadian Institutes of Health Research as well as by the Atlantic Innovation Fund in partnership with the Atlantic Canada Opportunities Agency, the Dalhousie Medical Research Foundation, and the Queen Elizabeth II Health Sciences Centre Foundation. E.B. was supported by a postdoctoral fellowship from the Nova Scotia Health Research Foundation. We are grateful to Dr. M. E. Hatten (The Rockefeller University, New York, NY) and the GENSAT Project for the gift of the GAD65::GFP mice. We thank Drs. Frederic Bretzner and Pratip Mitra for their comments on the manuscript, and Angelita Alcos, Nadia Farbstein, Bithika Ray, and Haiyun Zhang for their excellent technical assistance.

Correspondence should be addressed to Robert M. Brownstone, Departments of Surgery and Anatomy \& Neurobiology, Faculty of Medicine, Dalhousie University, Sir Charles Tupper Medical Building, 5850 College Street, Halifax, NS B3H 1X5, Canada. E-mail: rob.brownstone@dal.ca.

DOI:10.1523/JNEUROSCI.1401-09.2010

Copyright $\odot 2010$ the authors $\quad 0270-6474 / 10 / 301137-12 \$ 15.00 / 0$
Jordan, 1987). However, motoneurons still receive rhythmic inhibition during locomotion in animals in which V1-derived neurons have been silenced (Gosgnach et al., 2006). The non-V1 neurons that are responsible for postsynaptic inhibition of motoneurons during locomotion have not been defined.

Several populations of last-order inhibitory interneurons have been defined in the cat. In addition to RCs and IaINs, at least two classes of inhibitory interneurons have been defined in intermediate laminae, including medial laminae V/VI (Czarkowska et al., 1981; Jankowska et al., 1981; Brink et al., 1983; Rudomin et al., 1987). These populations receive low-threshold primary afferent input and are comprised of both GABAergic and glycinergic neurons, with some projecting to Clarke's column (Hongo et al., 1983a,b; Rudomin et al., 1990). In addition, other populations of inhibitory interneurons have been identified (Jankowska, 1992; Cabaj et al., 2006), some of which are active in locomotion (Shefchyk et al., 1990; Quinlan and Kiehn, 2007). The intrinsic properties of these various populations of identified interneurons and their role(s) in locomotor networks have yet to be defined.

To study neuronal properties and roles during locomotion, transgenic mice in which fluorescent proteins are expressed in subpopulations of neurons can be used (e.g., Wilson et al., 2005). Mice in which the expression of green fluorescent protein (GFP) is driven by one of the glutamic acid decarboxylase (GAD65 or GAD67) isozymes responsible for synthesis of GABA has led to the identification of interneurons involved either in pain pathways (Hantman et al., 2004; Dougherty et al., 2009) or in presyn- 
aptic inhibition of Ia afferents (Hughes et al., 2005; Betley et al., 2009). However, there is no evidence that GFP + neurons in these animals postsynaptically inhibit motoneurons.

Given the many GABAergic terminals in apposition to motoneuronal somata that do not derive from the V1 population (Alvarez et al., 2005), and the fact that V1 neurons are not alone responsible for motoneuronal inhibition during locomotion (Gosgnach et al., 2006), we sought animals in which GFP is expressed in non-V1-derived interneurons with terminals in apposition to motoneurons. Using GAD65::GFP transgenic mice, we describe GFP-expressing neurons in medial laminae V/VI. We illustrate their basic anatomical and electrophysiological properties and demonstrate that they receive low-threshold primary afferent input and are rhythmically active during fictive locomotion. These data indicate that these neurons may be one source of rhythmic inhibition to motoneurons during locomotion.

\section{Materials and Methods}

All procedures were approved by the Dalhousie University Animal Care Committee and conform to the standards of the Canadian Council for Animal Care.

Animals. GAD65::GFP mice were obtained from the Gensat project at the University of Rockefeller (www.gensat.org). These mice were generated using BAC technology (Gong et al., 2003) where the expression of enhanced GFP is driven by the promoter for GAD65.

Immunohistochemistry. Two- to four-week-old mice were transcardially perfused with $0.9 \%$ saline followed by $4 \%$ paraformaldehyde in $0.1 \mathrm{M}$ phosphate buffer (PB; pH 7.4). Spinal cords were removed, postfixed in $4 \%$ paraformaldehyde solution overnight and subsequently cryoprotected overnight in 30\% sucrose. Fifty-micrometer spinal cord sections were cut and incubated, at room temperature for $16-24 \mathrm{~h}$, in one or more of the following primary antibodies: mouse or sheep anti-GFP (1:500, Biogenesis), goat anti-Fos (1:1000, Millipore Bioscience Research Reagents), mouse anti-GAD65 or -GAD67 (1:500), guinea-pig antiVGluT1(1:2500), and/or goat anti-choline acetyltransferase (ChAT) (1: 100, all from Millipore Bioscience Research Reagents), and guinea-pig anti-GlyT2 (1:5000, Sigma) as previously described (Wilson et al., 2005). Sections were then washed in PBST $(0.1 \mathrm{M}$ phosphate buffer, $0.9 \%$ sodium chloride, and $0.3 \%$ Triton X-100) and incubated in the appropriate secondary antibodies conjugated to either Alexa 488, 555, or 647 (1:250, Invitrogen) for $2-3 \mathrm{~h}$ at $4^{\circ} \mathrm{C}$. Sections were mounted and coverslipped with an antifade mounting medium (Vectashield, Vector Laboratories).

Image acquisition. Confocal images were acquired with an inverted Zeiss Axiovert 100 м equipped with a LSM510 or LSM510-META scanhead (Zeiss Jena). The microscopes were equipped with $25-100 \times$ oilimmersion objectives. Alexa 488 fluorophore was excited with an argon 458/488 laser, Alexa 555 with a helium-neon 543 laser, and Alexa 647 with a red diode 633 laser. Appropriate emission filter sets (bandpass 510-550 for Alexa 488, bandpass 560-610 nm for Alexa 555, and a long-pass $615 \mathrm{~nm}$ for Alexa 647) ensured distinction between the fluorophores. Images obtained measured $1024 \times 1024$ pixels, with each pixel representing $0.09 \mu \mathrm{m}$. Immunostaining was analyzed on single optical sections and on projection stacks consisting of 2-20 sections. As the smallest puncta of interest had $z$-axis measurements in the range of several micrometers, optical sections were obtained at $0.9-1.1 \mu \mathrm{m}$ $z$-intervals through the point of interest. High-magnification images from single optical sections were obtained with a $100 \times$ objective and upto $7 \times$ digital zoom feature on the microscope software. This permitted detailed comparison of the two fluorophores. Figures were prepared using Adobe Photoshop with minimal adjustments of brightness and contrast.

Electrophysiological recordings. Postnatal (P6-P14) GAD65::GFP mice were deeply anesthetized with ketamine $(\mathrm{mg} / \mathrm{kg}$, i.p.) and decapitated, and the spinal cords were removed under cold $\left(<4^{\circ} \mathrm{C}\right)$ calcium-free sucrose-substituted artificial CSF (aCSF) detailed by Jiang et al. (1999a). Transverse spinal cord slices $(250 \mu \mathrm{m})$ were cut with a vibrating microtome (Vibratome 3000$)$ and transferred to warm $\left(32-37^{\circ} \mathrm{C}\right)$ aCSF con- taining the following (in $\mathrm{mM}$ ): $\mathrm{NaCl} 127 ; \mathrm{KCl} 1.9 ; \mathrm{MgCl}_{2} 1.3 ; \mathrm{CaCl}_{2} 2.4$; $\mathrm{NaH}_{2} \mathrm{PO}_{4} 2.4 ; \mathrm{NaHCO}_{3} 26$; D-glucose 10 and bubbled with $95 \% \mathrm{O}_{2}-5 \%$ $\mathrm{CO}_{2}$. After 20-40 min, a slice was transferred to the recording chamber and superfused with room temperature aCSF.

GFP neurons were identified under epifluorescence with a narrowband GFP filter (41020; Chroma Technology), and whole-cell patchclamp recordings were made assisted by differential interference contrast optics under infrared illumination on a Leica DMLFSA microscope (Leica Microsystems). Recordings were acquired with a MultiClamp 700A amplifier, Digidata 1322A analog to digital converter (Molecular Devices) and using pCLAMP software (version 9, Molecular Devices).

Recording electrodes (2-4 M $\Omega$ ) contained (mM): $\mathrm{KMeSO}_{4} 140 ; \mathrm{NaCl}$ 10 ; $\mathrm{CaCl}_{2} 1$; HEPES 10; EGTA 1; Mg-ATP 3. The $\mathrm{pH}$ was adjusted to 7.2 with $\mathrm{KOH}$. All drugs [NMDA $(5-10 \mu \mathrm{m})$, serotonin $(5-\mathrm{HT} ; 10 \mu \mathrm{m})$, dopamine $(50 \mu \mathrm{m})$, tetrodotoxin (TTX; $1 \mu \mathrm{m})]$ were added to the perfusate.

TMRD experiments. Spinal cords $(n=12)$ were removed, as above, from P6-P8 mice and pinned to a Sylgard dish that contained aCSF that was continuously bubbled with $\mathrm{O}_{2} / \mathrm{CO}_{2}$. Tetramethylrhodaminedextran (TMRD) crystals were applied to the cut end of the thoracic cord, and dye spread was prevented by a plastic bridge sealed to the low thoracic region with Vaseline. The cords were left for a period of $4-8 \mathrm{~h}$ for the dye to be taken up and retrogradely transported down the axons. The spinal cord was subsequently fixed in $4 \%$ paraformaldehyde overnight, and longitudinal sections were cut and processed for anti-GFP as above.

c-Fos experiments. To activate the activity-dependent immediate early gene $c$-Fos, adult mice were induced to walk in a running wheel for 90 min. Under control conditions, mice were kept in a quiet light environment for $2 \mathrm{~h}$, where they typically slept. Following either protocol, mice were perfused (as above), and their spinal cords were harvested and processed for Fos immunoreactivity.

Two-photon calcium imaging in the hemisected in vitro spinal preparation. The detailed methodology for these experiments was previously described (Wilson et al., 2007b). For the in vitro spinal cord preparation, postnatal mice (postnatal day 6) were deeply anesthetized with ketamine (100 mg/kg, i.p.), a laminectomy was performed, and their spinal cords were removed and hemisected through the midline to reveal the large GFP + interneurons that were typically located 50-150 $\mu \mathrm{m}$ deep to the cut surface. Suction electrodes were attached to ipsilateral upper lumbar ventral roots (Jiang et al., 1999b) and/or dorsal roots (DR) and recordings were obtained at $30-32^{\circ}$.

GFP+ neurons in upper and mid-lumbar segments were loaded with Fluo-3 AM (Invitrogen) using a pressure injection technique similar to that described by (Stosiek et al., 2003) and recently applied to the spinal cord (Wilson et al., 2007b). Interneurons were subsequently visualized with an upright Zeiss Axioskop microscope equipped with a LSM510 NLO Meta scan head (Carl Zeiss) and an ultrafast tunable Ti:sapphire laser (Chameleon XR, Coherent). Reflected light was directed to nondescanned detectors (R6357, Hamamatsu Photonics).

GFP+ interneurons could be readily identified (Wilson et al., 2007b), and time series of fluorescent images of calcium activity were collected with the following parameters: $512 \times 512$ pixel images, digital zoom $4-8$ times with $40 \times$ objective (numerical aperture 0.8 ), 800 frames, $200-400$ $\mathrm{ms} /$ frame, $0.64 \mu$ s pixel dwell time, laser power $<50 \mathrm{~mW}$. Bidirectional scanning was used to increase scan speed, and scanners were always calibrated in the $x-y$ plane before each acquisition. A TTL pulse initiated at the start of the frame scan was digitized and captured by the acquisition software to synchronize the ventral root recording to the calcium imaging traces.

Calcium transients were recorded as changes in mean pixel intensity in a defined region of interest over time and expressed as the percentage change in fluorescence divided by the baseline fluorescence $(\Delta F / F)$. These data were analyzed in custom software developed at the Spinal Cord Research Centre, University of Manitoba (SCRC Data Capture and Analysis Software: http://www.scrc.umanitoba.ca/doc/) that ran on Mac OS X. This analysis package was modified to allow the alignment of the calcium imaging waveform with the TTL pulses, and thus with ventral root recordings or dorsal root stimulation.

Figures were compiled using SigmaPlot 9 and Photoshop. 


\section{Results}

Distribution of GABAergic interneurons in GAD65::GFP mice

In the adult mammalian spinal cord, GABAergic neurons are found in all laminae, except lamina IX (Barber et al., 1982). In addition, all laminae contain GABAergic terminals (McLaughlin et al., 1975; Mackie et al., 2003). Thus, it would be expected that there are many different populations of GABAergic interneurons with distinct functions. To study a subpopulation of these GABAergic interneurons, we have used a strain of GAD65::GFP BAC transgenic mice, developed through the GENSAT project (www.gensat.org). In these mice, a subpopulation of GABAergic interneurons expresses GFP under the control of the promoter for GAD65.

GFP-positive GABAergic interneurons were observed along the entire length of the spinal cord. In the transverse plane, two distinct regions containing GABAergic interneurons were observed, those in medial laminae V/VI (Fig. 1A, B), and those in the superficial dorsal horn (Fig. $1 A, C$ ). Note that, given the distribution of GAD65 in the spinal cord (Mackie et al., 2003), there are likely many neurons that express GAD65 that are not GFP + . The confined expression of GFP in this strain of transgenic animals allows for the study of these specific populations.

The GFP + neurons in the superficial dorsal horn were evenly distributed in the superficial dorsal laminae and were morphologically homogeneous comprising small, bipolar neurons. Given the location of these superficial GABAergic interneurons, it is possible that they are associated with local afferent processing such as inhibitory transmission to substantia gelatinosa neurons (Yoshimura and Nishi, 1995). It has been shown that small inhibitory cells in the superficial dorsal horn are mostly related to processing ascending sensory information by modulating neurotransmitter release from the central terminals of primary afferents (Lao and Marvizon, 2005) and being the substrate for lateral inhibition in ascending sensory systems (Le Bars, 2002; Heinke et al., 2004; Graham et al., 2007). Heinke et al. (2004) suggested that GFP-positive cells in laminae I and II in GAD67-GFP transgenic mice are involved in the transmission of nociceptive information to the brain.

The GABAergic interneurons located in medial laminae V/VI often formed distinct clusters with infrequent additional GFP+ neurons distributed across laminae V/VI (Fig. $1 A, B, F$ ). In addition, occasional neurons of similar morphology were also observed in lamina IV. These neurons are located in the same region as group I nonreciprocal inhibitory interneurons in the cat (Jankowska et al., 1981; Brink et al., 1983; Walmsley, 1991) as well as neurons identified in the mouse that are responsible for presynaptic inhibition of group Ia afferent transmission to motoneurons (i.e., supply P-boutons) (Hughes et al., 2005; Betley et al., 2009). In addition to studying morphological features, we therefore studied whether these GFP + neurons have properties similar to either of those populations. Specifically, we studied whether the GFP+ neurons (1) express inhibitory transmitters; (2) make axoaxonic synapses with group Ia afferents; (3) project to motoneurons; (4) project to dorsal spinocerebellar tract (DSCT) neurons; (5) innervate other GABAergic interneurons within this group; (6) have characteristic electrophysiological properties; (7) are contacted by group I afferents; and (8) are involved in the spinal locomotor network.
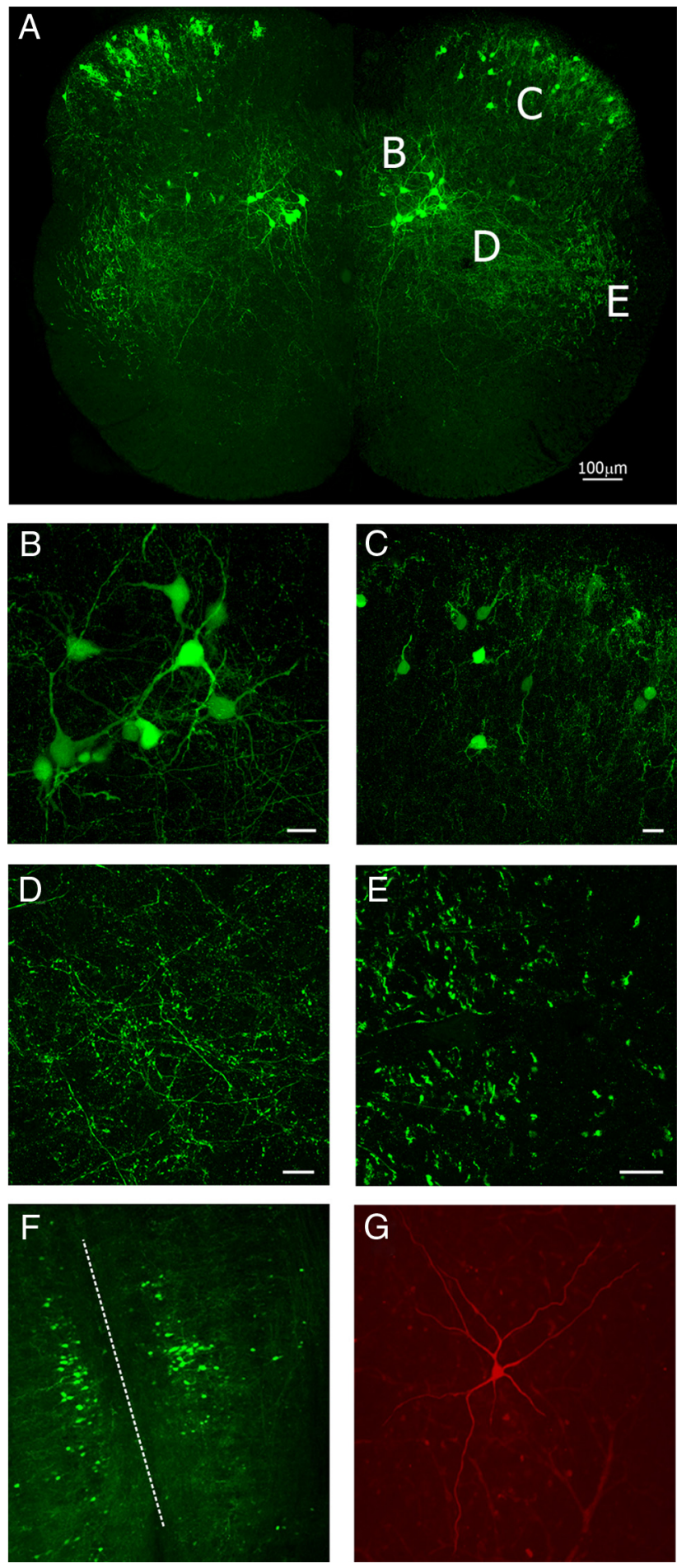

Figure 1. Distribution and morphology of GFP + neurons. A, Low-power photomicrograph of a cross section of upper lumbar spinal cord demonstrating cluster of GFP + neurons in medial lamina V/V $(\boldsymbol{B})$, smaller GFP + neurons scattered in superficial dorsal horn $(\boldsymbol{C})$, extensive GFP + processes in lamina VII (D), and the appearance of GFP + axonal cross sections in the lateral funiculus $(\boldsymbol{E})$. $\boldsymbol{F}$, The medial lamina V/VI GFP + neurons appear clustered in longitudinal horizontal cross sections. The dashed line approximates the midline. G, Morphology of a GFP+ neuron demonstrated following intracellular fill (in slice) with Neurobiotin demonstrating extensive multipolar dendrites.

\section{Morphological heterogeneity of lamina V/VI GABAergic interneuron population}

Neuronal somata of clustered lamina V/VI GABAergic interneurons exhibited a variety of somatic shapes and ranged in diameter 
from 10 to $40 \mu \mathrm{m}$ (Fig. $1 \mathrm{~B}$ ). Of 360 neurons, 137 were classified as oval (38\%), 113 pyramidal (31\%), and 46 round (13\%). Approximately $18 \%(64)$ of the neurons had intermediate neuronal shapes that could not be readily classified into one of these categories (Fig. $1 B$ ). The pyramidal and oval shaped neurons were typically large neurons, while the round neurons were often smaller than $15 \mu \mathrm{m}$.

The dendritic morphology was examined by injection of Neurobiotin during whole-cell patch-clamp recordings in transverse spinal cord slices and subsequently visualized using avidinrhodamine $(n=25)$ (Fig. $1 G)$. The dendritic arborizations in the dorsoventral plane of all lamina V/VI GABAergic interneurons were fairly extensive. Typically, two to four large primary processes extended in different directions from the neuronal somata, and each process branched two to three times within $50-80 \mu \mathrm{m}$ of the soma. Dendritic branches could be traced for distances of 100-300 $\mu \mathrm{m}$ from the somata with the most striking branches coursing in the ventral and lateral directions. Qualitatively, larger somatic diameters were correlated with more extensive dendritic trees. Only in one neuron were processes seen to cross to the contralateral side. It is possible that the detection of contralateral processes was limited due to the use of slice preparations.

\section{Axonal projections of lamina V/VI GABAergic interneurons}

In transverse spinal sections, the lateral funiculus contained dense plexuses of cut GFP + fibers (Fig. $1 E$ ). In longitudinal sections, long fibers coursed parallel to each other in the lateral funiculi. When injected in the hemisected spinal cord, intracellular fills of lamina V/VI GABAergic interneurons revealed processes that projected to the lateral funiculi, where they bifurcated, sending branches in both the rostral and caudal directions (Fig. 2A).

To demonstrate further that the lamina V/VI GAD interneurons are the source of the GFP fibers in the lateral funiculi, TMRD was applied to the mid-low thoracic region of the spinal cord in the in vitro spinal cord preparation. Retrograde transport of TMRD revealed somatic labeling of lamina V/VI GABAergic interneurons close to the site of TMRD application; however, despite transport of the dye to lower lumbar regions, very few lamina V/VI GABAergic interneuronal somata were labeled (Fig. $2 B)(n=9$ mice $)$. Further, addition of TMRD to the sacral region ( $n=3$ mice) revealed occasional GFP + interneurons in the lumbar region that contained the dye. Neurons greater than two segments from the site of injection were seldom labeled. Together with the intracellular fills and the presence of dense, longitudinally orientated, GFP-positive axonal fibers in the lateral part of the lateral funiculi, these data indicate that lamina V/VI GABAergic interneurons have short intersegmental axons, thus classifying at least a population of them as short propriospinal neurons.

To understand the implications of activity in these neurons, it is necessary to know where these axons terminate. Intracellular fills in the transverse plane failed to reveal axon terminals. This may be due to the fact that the axons are not contained within the $250 \mu \mathrm{m}$ slice (see above), or to a lack of dye in the terminals. Therefore, axon terminals of lamina V/VI GABAergic interneurons were identified immunohistochemically with antibodies against GFP, and GABAergic or glycinergic terminal proteins (GAD65, GAD67, or GlyT2). GFP+ bouton-like structures were located in high density throughout lamina VII (Fig. 1D), and lower density in laminae VIII and IX. Some terminals were found in the dorsal horn. Double-labeled terminals (GFP, GAD65) were most numerous in laminae VIII and IX (72\% of double-labeled
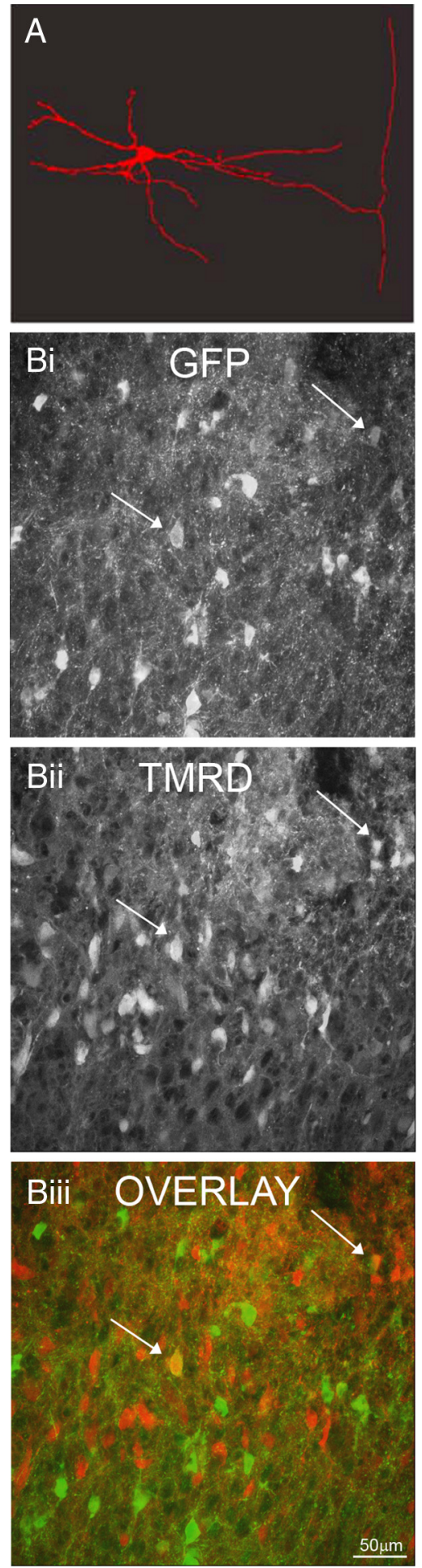

Figure 2. The medial GFP + neurons are propriospinal. $A$, Following intracellular fill with Neurobiotin in the hemisected spinal cord followed by tissue sectioning, an axon can be seen extending into the lateral funiculus, where it bifurcates into rostral and caudal branches. $\boldsymbol{B}, \mathbf{L a}$ beling with TMRD 2-4 segments rostral or 4-6 segments caudal to study demonstrated few neurons labeled with both GFP (Bi) and TMRD (Bii, overlay in Biii, arrows).

terminals), followed by lamina VII (21\%), and lamina VI (5\%, 8 sections, 198 terminals).

Many GABAergic neuronal terminals also contain the synthetic enzyme for GAD67 (Esclapez et al., 1994; Soghomonian and Martin, 1998). Double-label immunohistochemical studies of GAD67 with GFP revealed very dense labeling in both the 

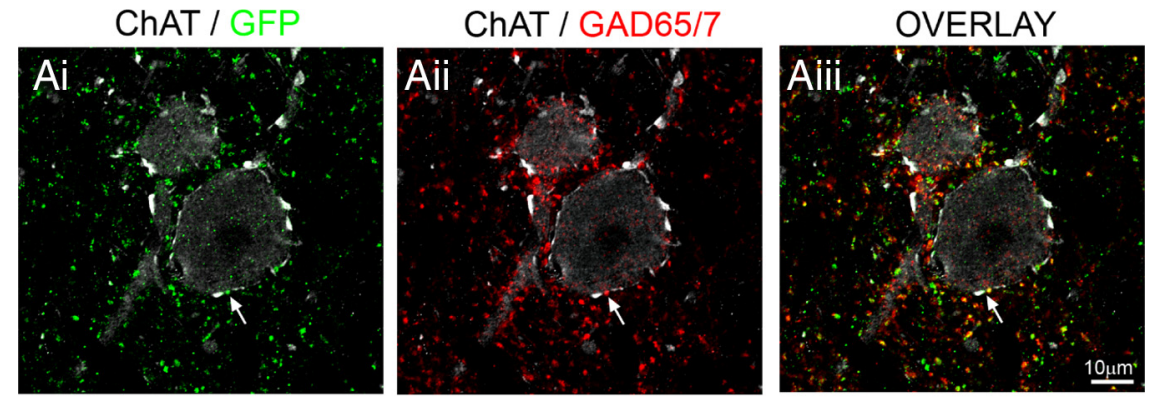

ChAT / GFP

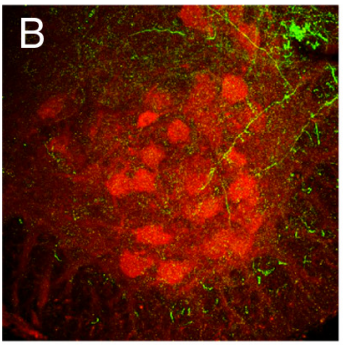

GFP
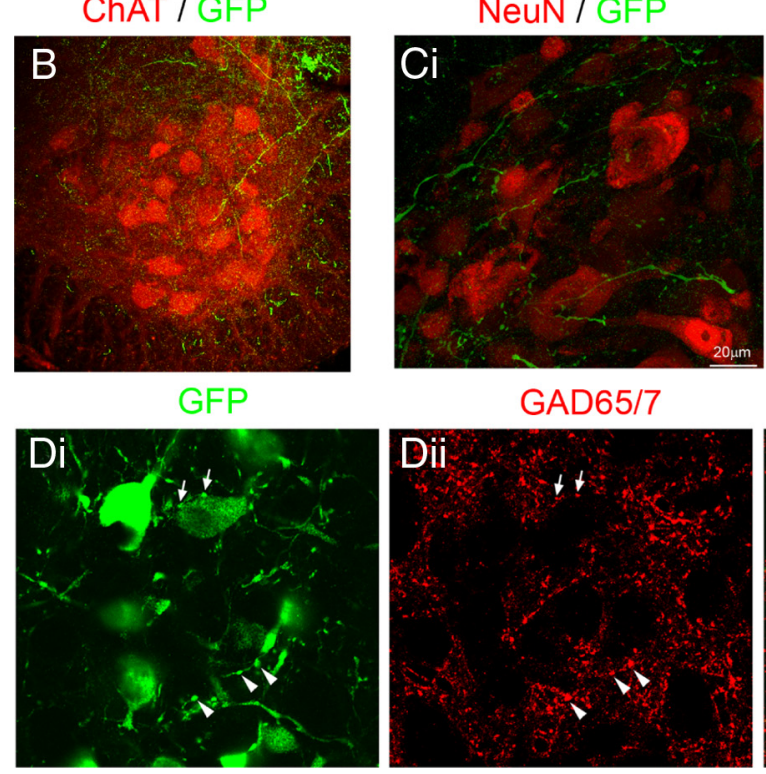

GAD65/7
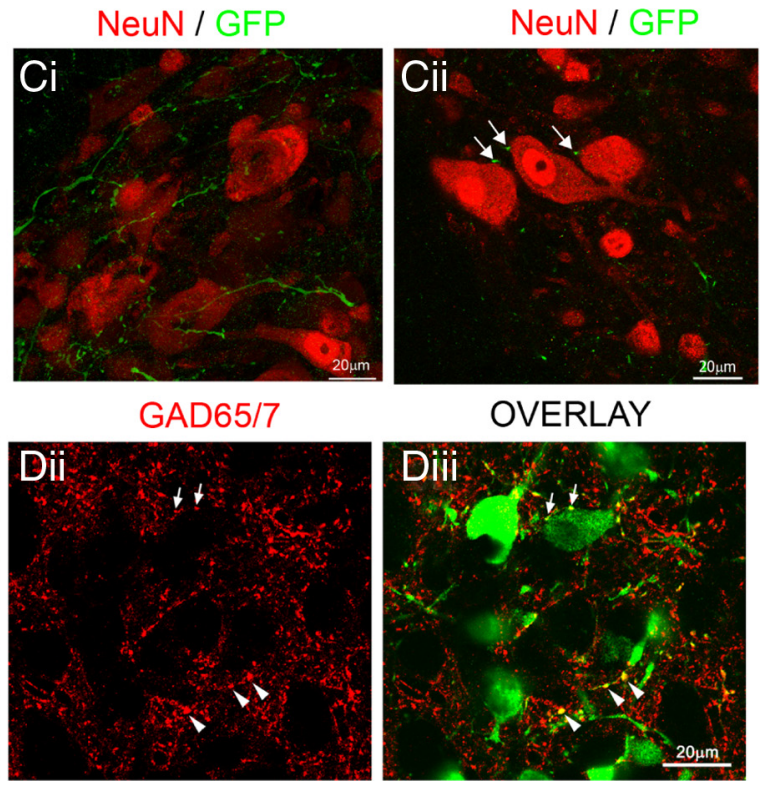

OVERLAY

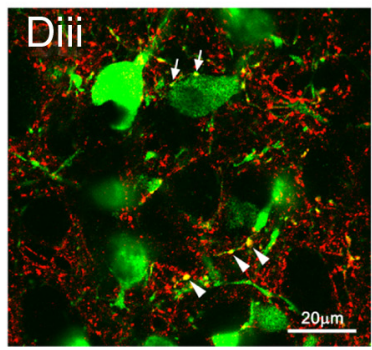

Figure 3. Spinal targets of medial GFP + neurons. $A$, Motoneurons were identified by ChAT immunohistochemistry (white) $\mathrm{GFP}+(\boldsymbol{A i}, \mathbf{A i i i )})$ and GAD + (Aii, Aiii) boutons (arrows) were identified in apposition to motoneurons following the identification of GFP + axons coursing into the ventral horn (B). Ci, Axons were also identified coursing into the region of large neurons in Clarke's column, upon which bouton-like structures (arrows) were identified (Cii). D, GFP + (Di) and GAD+ (Dii) boutons (arrows) were also identified on medial GFP + neurons (Diii, overlay).

dorsal (especially in laminae V/VI) and ventral (laminae VII-IX) spinal cord. Of 361 double-labeled boutons, $12 \%$ were located in laminae I-IV, 45\% in laminae V-VI, 25\% in lamina VII, and 17\% in lamina VIII or IX.

As many GABAergic interneuron axon terminals also contain glycine, the possibility that the GABAergic interneuronal terminals also contained the glycine transporter protein GlyT2 (Dumoulin et al., 2000) was investigated ( $n=5$ mice). However, double-labeling immunohistochemistry revealed few GFP-positive axon terminals in lamina VI, VII, or IX that contained GlyT2 (1-2 per section, data not shown). Similarly, to determine whether the GFP+ neurons are glutamatergic, double-label immunohistochemistry experiments using antibodies against GFP and the glutamate transporter VGLUT2 were performed ( $n=4$ mice). No double labeling was seen, indicating that the GFP+ neurons are not glutamatergic. We therefore focused on antiGAD labeling for the analysis of terminals.

Primary spindle afferent (Ia) input to motoneurons is gated by presynaptic inhibition and the neurotransmitter responsible for this modulation is GABA (Rudomin and Schmidt, 1999). These GABAergic axon terminals (termed P-boutons) form axoaxonic synapses on Ia afferent fiber axon boutons, the terminals of which are identifiable with immunohistochemistry against VGLUT1 (Hughes et al., 2005). P-bouton terminals are GAD65 positive, and the GABAergic spinal neurons from which they originate have been identified and are also located in laminae V/VI (Hughes et al., 2005; Betley et al., 2009). To determine whether the GFP-positive neurons in our GAD65::GFP strain are also a source of P-boutons, we looked for immunohistochemical colabeling of GFP and GAD65 on primary afferents identified with VGLUT1. In the ventral horn, P-boutons were readily identified, however we did not observe any GFP-positive P-boutons (data not shown). Therefore GFP-expressing neurons in this strain of GAD65:: GFP mice do not participate in the presynaptic inhibition of group Ia primary afferent synapses on motoneurons.

\section{Projections of GABAergic interneurons to known cell types}

To identify whether the GFP+ neurons are last order, we focused on lamina IX, where long axons with boutons were often observed (Fig. 3B). GFP+ terminals were identified with antibodies against both GAD65 and GAD67, and studied in sections in which motoneurons were identified with ChAT antibodies. In lamina IX, GFP and GAD65 or GAD65/7 double-positive terminals were distributed throughout the motor pools and were frequently observed in direct apposition to motoneuron somata (Fig. $3 A$ ). As there are no known projections to these regions from the superficial dorsal horn, it is probable that these terminals arise from lamina V/VI GABAergic interneurons. However, we cannot exclude that these boutons may arise from descending GABAergic neurons (Holstege, 1991).

DSCT neurons are large distinguishable neurons located in Clarke's column in the thoracolumbar cord and can be readily identified based on size and location (Alvarez et al., 2005). To obtain a clear demarcation of their somatic boundaries, we used the neuronal marker NeuN (Alvarez et al., 2005). Many thin $\mathrm{GFP}+$ fibers with profuse axonal terminals were observed in Clarke's column (Fig. 3Ci) and single terminal-like structures were observed apposing the somata of large NeuN-labeled putative DSCT neurons (Fig. 3Cii). Thus these data suggest that some lamina V/VI GABAergic interneurons also innervate DSCT neurons (cf. Hongo et al., 1983a).

Given evidence that other inhibitory interneuronal types, such as group I nonreciprocal inhibitory interneurons in the cat, innervate each other (Brink et al., 1983), we looked for GFP + terminals identified with anti-GAD67, in the region of lamina V/VI GABAergic interneurons. Indeed, we found many double-positive terminals on somata of these GFP + interneurons (Fig. 3D).

Together, these data indicate that, as a population, these lamina V/VI GABAergic interneurons project to motoneurons, to DSCT neurons, and reciprocally innervate each other. Whether these are one population or several subpopulations remains to be determined. 


\section{Electrophysiological properties of} lamina V/VI GABAergic interneurons The electrophysiological properties of neurons determine both their integrative capacity and their contribution to network activity. Therefore whole-cell patchclamp recordings were obtained from lamina V/VI GABAergic interneurons in spinal cord slices and their intrinsic properties investigated (Fig. 4). The resting membrane potential of lamina V/VI GABAergic interneurons $(n=41)$ ranged between -40 and $-75 \mathrm{mV}$ (mean $-54 \pm$ $8.1)$. The whole-cell capacitance $\left(C_{\mathrm{m}}\right)$ and membrane resistance $\left(R_{\mathrm{m}}\right)$ ranged from 10 to $79 \mathrm{pF}(37.9 \pm 15.0 \mathrm{pF})$ and from 60 to $1500 \mathrm{M} \Omega(581.3 \pm 455.4 \mathrm{M} \Omega)$, respectively. Accordingly, membrane time constants ranged from 3 to $75 \mathrm{~ms}(19.4 \pm 15.8$ $\mathrm{ms})$. Although this variability in passive electrophysiological properties may in part be due to the loss of neuronal membrane associated with slicing, it corresponds to the morphological variability seen in this pool of neurons.

In some studies, neurons have been classified dependent on their firing patterns (e.g., Szûcs et al., 2003). For example, firing patterns of interneurons in the ventral region of the juvenile rat spinal cord have been classified into three types: repetitive, phasic, and single-spiking (Theiss and Heckman, 2005). Of the 35 lamina V/VI GABAergic interneurons with stable depolarizing responses, 31 (89\%) fired action potentials continuously during depolarization (Fig. $4 B$ ). Three neurons were either phasic $(n=2)$ or fired only single action potentials $(n=1)$, and only a single neuron had a delay to the onset of repetitive firing. There was no clear morphological predictor (soma size or shape) of response to current injection. Most of the recorded neurons exhibited clear spike accommodation during a $1 \mathrm{~s}$ current pulse (Fig. $4 B$ ).

Lamina V/VI GABAergic interneurons expressed three obvious combinations of intrinsic properties revealed by injections of hyperpolarizing current pulses. The first group of neurons responded with an Ih-like (sag) conductance (27/37). Of these, 12 had an obvious depolarizing sag followed by a rapid rebound following release of the hyperpolarizing pulse that reached firing for action potential firing (Fig. 4Ai). An additional 15 neurons expressed a clear Ihlike conductance on hyperpolarization, but had little rebound on the break of the hyperpolarizing current pulse. The second group (4/37) did not have an obvious sag potential, but had a rebound potential similar to that seen in the first group (Fig. 4Aiii). The third group (6/37) had neither a sag nor a rebound potential (Fig. 4 Aii). There was no apparent relation between the responses to depolarizing and hyperpolarizing current injection. The divergence of electrophysiological properties may be related to the
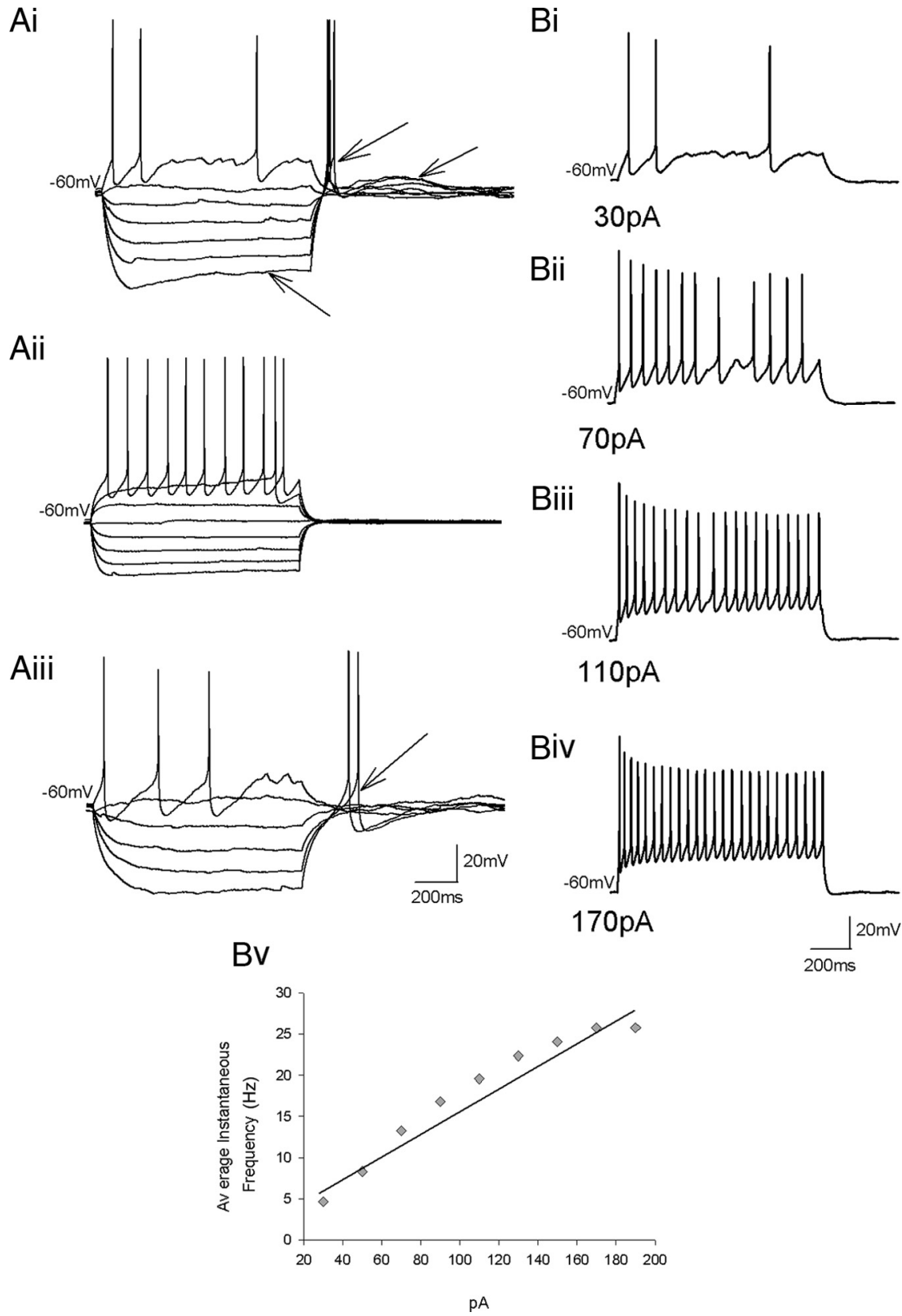

Figure 4. Electrophysiological properties of medial GFP + neurons. $A$, Three different neurons demonstrating a depolarizing sag (arrow) followed by an early rebound potential producing action potentials, and associated with a later, slower rebound depolarization (arrows) (Ai); neither a sag potential nor rebound (Aii); and absence of a sag potential, but an early rebound potential (arrow) producing action potentials (Aiii). Note the large postspike afterhyperpolarizations. $\boldsymbol{B}$, Another neuron demonstrating an increase in firing with depolarization (Bi-Biv), producing a linear frequency-current relation $(\mathbf{B v})$.

expression of a particular GAD isozyme (Feldblum et al., 1993; Soghomonian and Martin, 1998).

To determine the input:output relation of the neurons, the frequency of action potential firing was plotted against the current injected (Fig. $4 B)(n=9)$. There was a linear relation of the $f-I$ curves $\left(r^{2}=0.97 \pm 0.02\right.$, range $\left.=0.92-0.99\right)$, with slopes ranging from 107 to $350 \mathrm{~Hz} / \mathrm{nA}$ (mean $223.2 \pm 92.2 \mathrm{~Hz} / \mathrm{nA}$ ). As expected, the frequencies reached a plateau at higher stimulus strengths. Together, these data indicate that these neurons have heterogeneous electrophysiological properties, but under these conditions, the output of all neurons increased linearly in relation to their input, provided as current injected through the pipette. 

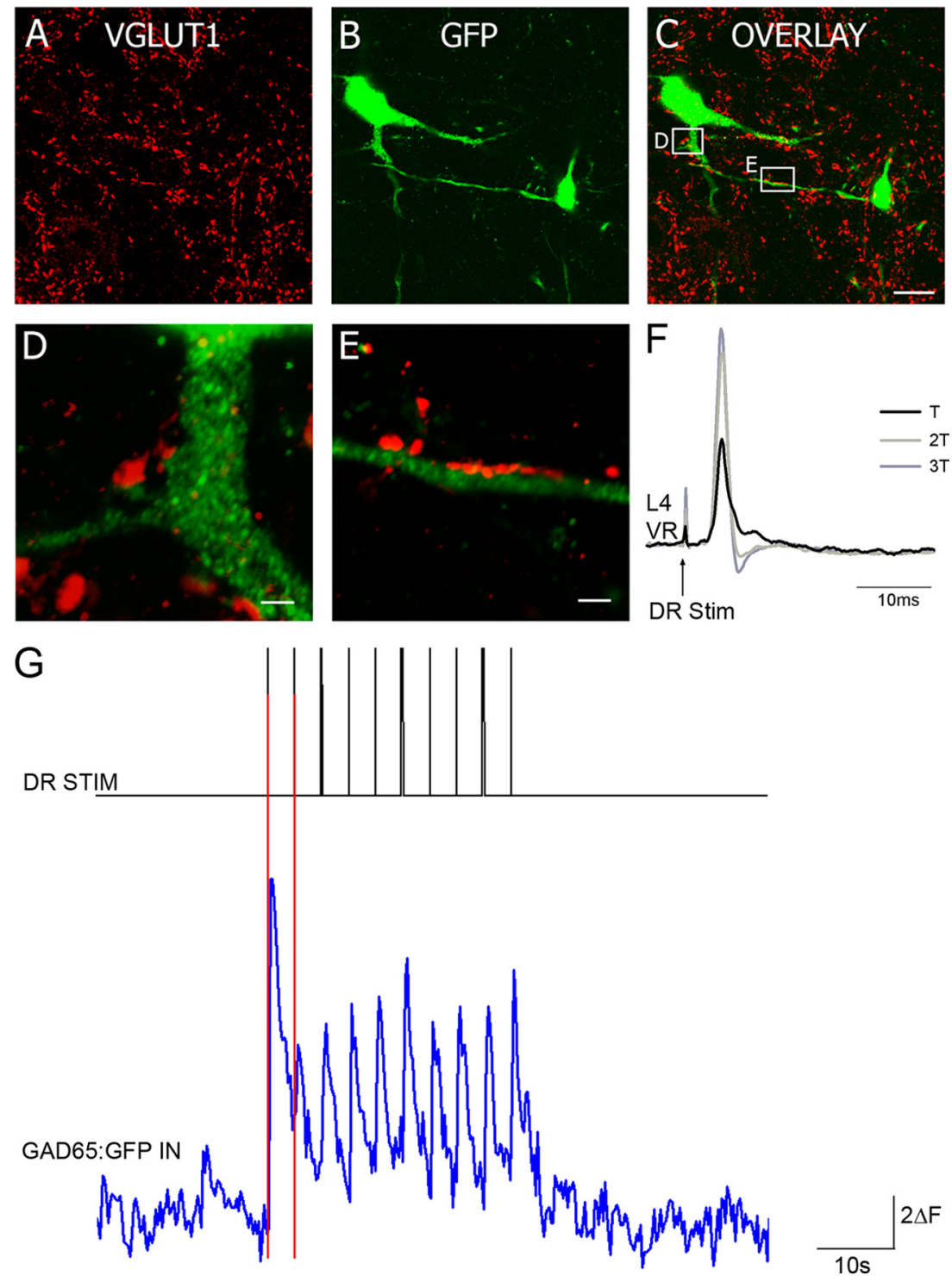

Figure 5. Medial GFP + interneurons (IN) receive primary afferent input. $\boldsymbol{A}$, Primary afferent boutons were identified by expression of VGLUT1, and were found in apposition to GFP + $(\boldsymbol{B})$ neurons ( $\boldsymbol{C}$, overlay). Higher magnification of the areas indicated in $\boldsymbol{C}$ demonstrate bouton-like structures along large $(\boldsymbol{D})$ and small $(\boldsymbol{E})$ dendritic branches. $\boldsymbol{F}$, The threshold for afferent stimulation (stim) in the hemisected spinal cord was determined as the strength of dorsal root stimulation required to elicit a monosynaptic response in the ventral root. G, Stimulation strengths of up to $2 \times$ threshold were used to demonstrate responses in medial GFP + neurons. The upper trace demonstrates the stimuli, and the lower trace demonstrates calcium transients measured using twophoton excitation microscopy, having loaded the neurons with Fluo-3.

\section{Input to lamina V/VI GABAergic interneurons}

We next examined whether these neurons receive primary afferent input. As myelinated primary afferent terminals contain VGLUT1 (Todd et al., 2003; Hughes et al., 2004), immunohistochemistry against VGLUT1 can be used to identify potential primary afferent input to spinal cord neurons. In double-label immunohistochemistry studies with antibodies against VGLUT1 and GFP, large and elongated VGLUT1-positive terminals were observed in high density apposing the somata and proximal dendrites of lamina V/VI GABAergic interneurons (Fig. 5A-E), thus supporting the hypothesis that lamina V/VI GABAergic interneurons receive primary afferent input. Interestingly, although these neurons are located in a region that is rich with VGLUT1 immunoreactivity, terminals were not observed on all GFP + somata, indicating that more than one population of neurons in this region may express GFP.

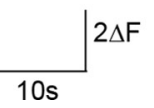

To study whether these lamina V/VI GABAergic interneurons receive functional primary afferent input, the dorsal roots were electrically stimulated in the hemisected spinal cord preparation. The response was monitored in lamina V/VI GABAergic interneurons with a calcium indicator dye imaged with two-photon excitation laser scanning microscopy (Wilson et al., 2007b). Threshold was determined as the minimum stimulus required to evoke a monosynaptic response in the ventral roots (Fig. $5 F$ ). These ventral root responses have fixed latencies despite increasing stimulus intensities, and there are no failures, indicating that they are monosynaptic responses as expected. Single stimuli of the dorsal roots at threshold were found to evoke large amplitude calcium transients in lamina V/VI GABAergic interneurons (Fig. 5G). These calcium responses were repeatable upon subsequent stimulation trials and showed no failures (Fig. 5G). The rise in calcium activity was always observed in the frame completed immediately following the stimulus (200-400 ms/frame acquisition time). Thus, following primary afferent stimulation, lamina V/VI GABAergic interneurons likely reach threshold for action potential generation, recorded as an increase in calcium activity.

Nearby GFP-negative neurons that were loaded with calcium indicator, some of which were spontaneously active did not reliably respond to DR stimulation. That is, although calcium transients were sometimes recorded, they were inconsistent, and did not necessarily occur within the first frame after the stimulus. It is likely that these neurons either receive input that is polysynaptic or subthreshold, or that the transients were unrelated to the stimulus. This was strikingly different from the calcium transients observed in the GFP+ neurons (described above). These data together indicate that lamina V/VI GABAergic interneurons receive input from segmental dorsal root afferents. This input is sufficient to consistently evoke calcium transients in these neurons, which, together with the anatomical data presented, leads us to suggest that they receive monosynaptic input from low-threshold primary afferents.

\section{Participation in locomotion}

Fos is commonly used as an activity-dependent marker (Konkle and Bielajew, 2004), and has been used to identify the location of neurons involved in locomotion (Dai et al., 2005; Wilson et al., 2005). It has been demonstrated that, following treadmill, spontaneous, and brainstem-evoked fictive locomotion, Fos expression increases in lamina VI of the lumbar spinal cord (Dai et al., 2005). To ascertain whether lamina V/VI GABAergic interneurons are involved in locomotion, the presence of Fos following locomotor and control (quiescent) tasks was investigated in 
lumbar spinal sections. In the control group, only 6/128 (5\%) lamina V/VI GFP + interneurons were Fos positive (Fig. $6 A$, top) $(n=2$ mice). In the locomoting group, 75/169 (44\%) lamina V/VI GABAergic interneurons were Fos positive (Fig. 6A, bottom) ( $n=2$ mice). This represents an approximately ninefold increase in the proportion of neurons expressing Fos, and supports the hypothesis that lamina V/VI GABAergic interneurons are active during overground locomotion.

Rhythmic and alternating output that mimics locomotion can be induced in the in vitro spinal cord with the addition of the neurotransmitters NMDA, 5-HT, and dopamine (Jiang et al., 1999a). Therefore, to determine whether lamina V/VI GABAergic interneurons express conditional bursting properties, which may then participate in locomotor rhythmogenesis, we applied these neurotransmitters to the GABAergic interneurons during whole-cell patch-clamp recordings in slice. Under these conditions [serotonin $(10 \mu \mathrm{M})$, NMDA $(10 \mu \mathrm{M})$, and dopamine $(10 \mu \mathrm{M})]$, lamina V/VI GFP+ interneurons $(n=5)$ depolarized to reach threshold for action potential firing. The neurons fired regularly and with steadily increasing firing frequency (Fig. 6B). Upon washout, all neurons repolarized to resting levels and stopped firing. Application of the same transmitter substances in the presence of TTX $(5 \mu \mathrm{M})$ did not result in any subthreshold oscillatory activity (4/4 neurons; data not shown). Therefore, lamina V/VI GABAergic interneurons do not exhibit conditional bursting properties under these conditions.

To investigate whether a temporal relationship exists between the activity of lamina V/VI GABAergic interneurons and locomotor output, these interneurons were loaded with Fluo-3 in the hemisected spinal cord preparation, and calcium activity was monitored while recording the ipsilateral L2 ventral root output (Wilson et al., 2007b). In resting conditions, GFP+ lamina V/VI GABAergic interneurons in L3-4 had minimal low-amplitude spontaneous activity. Addition of the neurotransmitters NMDA $(5 \mu \mathrm{M}), 5-\mathrm{HT}(10 \mu \mathrm{M})$, and dopamine $(50 \mu \mathrm{M})$ induced stable rhythmic activity in the ventral root and in all GFP + interneurons stably recorded $(n=7)$ (Fig. 7$)$. To assess whether the rhythmic calcium transients were related to ventral root activity, we first assessed the degree of entrainment of the calcium signals to the ventral root output by calculating the frequency ratio of the duration of the step cycles (Kriellaars et al., 1994). As the durations of the step cycles were very similar between the ventral root bursts $(6131 \pm 664 \mathrm{~ms})$ and calcium transients $(6256 \pm 503 \mathrm{~ms}$, $n=7)($ Fig. $7 K)$, the frequency ratio was close to $100 \%$ (mean $=$ $102.5 \pm 7.3 \%$, range from 90.8 to $113.5 \%$ ) (Fig. $7 L$ ). Thus, each ventral root burst is correlated with a burst of activity in the interneuron. Note that by bulk loading Fluo-3 into the region where the lamina V/VI GABAergic interneurons are located, many nearby GFP-negative neurons were also loaded, and their activity in response to NMDA, 5-HT, and dopamine could be monitored. Although not systematically studied, many of these neurons were also rhythmically active with varying phases of peak activity (Wilson et al., 2007b).

Next, the onsets of the transients in GFP+ neurons were analyzed in relation to either the start time (Fig. $7 B, D, G, I, M$ ) or the termination (end) time (Fig. $7 C, E, H, J, N$ ) of the ventral root bursts. In all cells, the onset of the calcium transient was correlated with the ventral root bursts $(r>0.75)$ when analyzed either way. In $2 / 7$ neurons, the calcium transient began in the first $25 \%$ of the step cycle beginning with the L2 burst (Fig. $7 B, D$ ), in $4 / 7$ neurons it began in the second quarter (Fig. $7 G, I$ ), and in $1 / 7$ neurons in the third (Fig. $7 M$ ). That is, there was a wide distribution of calcium transient onsets in relation to the onset of the L2 burst. On the other hand when analyzed in relation to the termination of the L2 flexor-related burst, the neurons could be divided into two distinct groups. In 5/7 neurons, the onset of the transients began after L2 burst termination (Fig. $7 \mathrm{H}, \mathrm{J}, \mathrm{N}$ ), whereas in 2/7 neurons the transients began just before burst termination $\left(\sim 270^{\circ}\right)$ (Fig. $\left.7 C, E, N\right)$. These data suggest that these interneurons comprise at least two physiologically distinct classes that are rhythmically active with activity beginning either during the extensor (5/7) or late flexor (2/7) phase of fictive locomotion. We propose that these interneurons are partly responsible for terminating extensor and flexor motoneuron activity respectively.

\section{Discussion}

In this study, a GAD65::GFP line of transgenic mice was used to characterize inhibitory interneurons located in the medial aspect of laminae V/VI in the spinal cord. We provide evidence that these neurons receive primary afferent input, and have segmental 

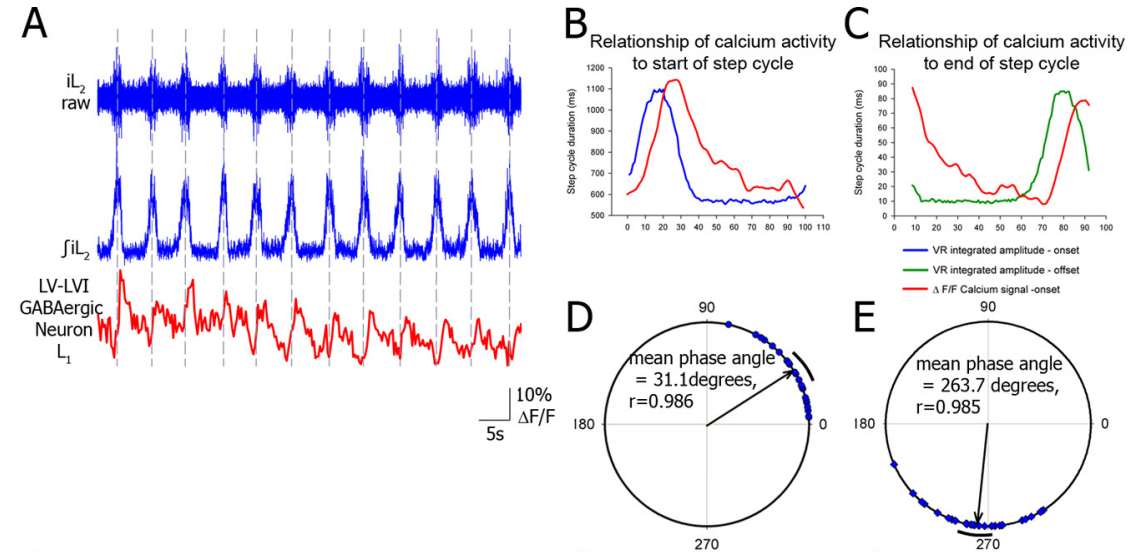

$\mathrm{F}$
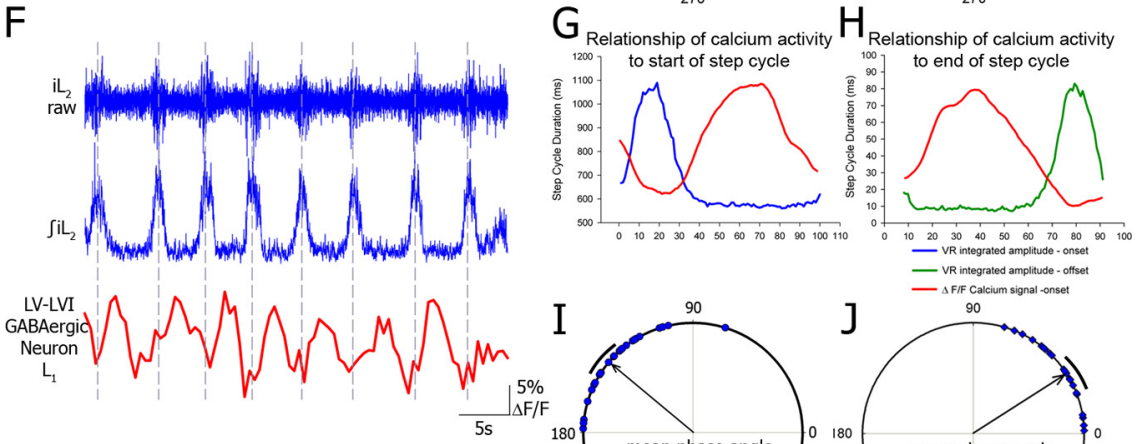

$\mathrm{K}$

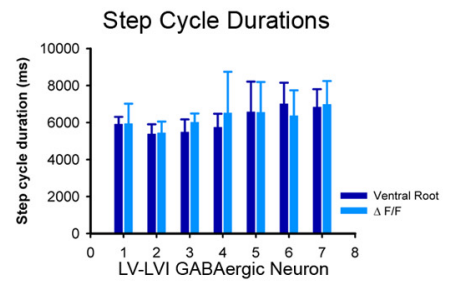

M

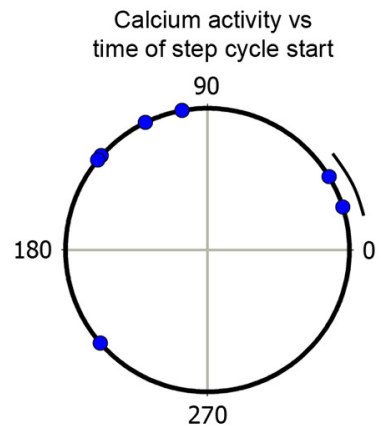$$
N
$$$$
\text { time of step cycle end }
$$

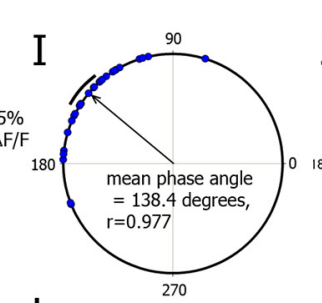

L Average Frequency Ratio
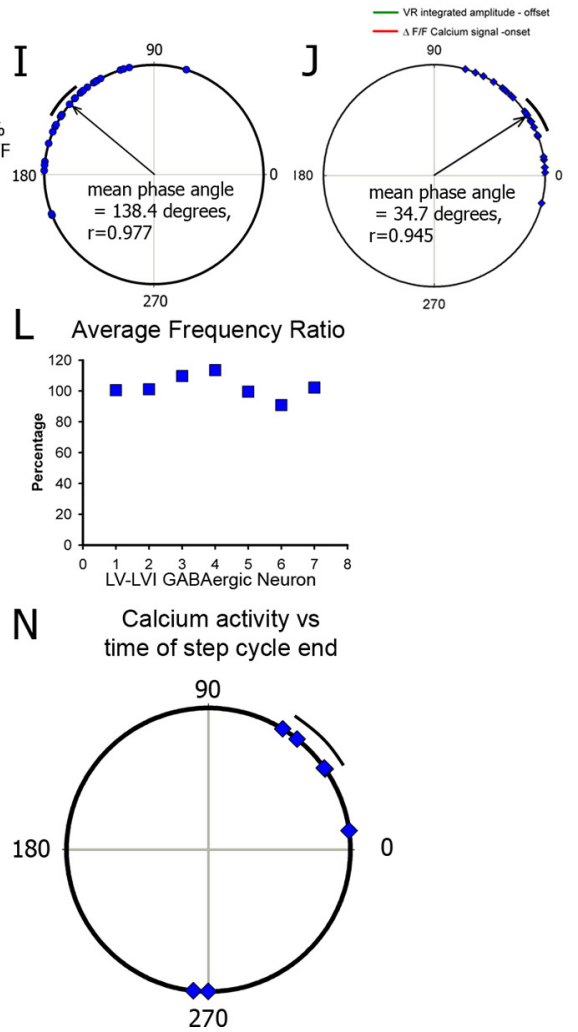

Figure 7. Medial GFP+ neurons are rhythmically active during fictive locomotion. A, Fictive locomotion was elicited in the hemisected spinal cord (top and middle traces are recordings from L2 ventral roots) while recording calcium transients in medial GFP+ neurons (lower trace). The calcium transients were averaged based either on the start $(\boldsymbol{B})$ or termination $(\boldsymbol{C})$ of the $L 2$ ventral root burst, demonstrating that the onset of the calcium transient was slightly delayed in relation to the onset of the ventral root burst. This delay can be seen in the polar plot $(\boldsymbol{D})$, in which $0^{\circ}$ is the onset of the ventral root burst and each point represents the onset of each calcium transient. The vector represents the mean, and the curved arc represents the time to capture a single frame. In the plot in $\boldsymbol{E}, 0^{\circ}$ represents the termination of the ventral root burst. $\boldsymbol{F}-\boldsymbol{J}$, Another GFP + neuron recorded and analyzed as in $\boldsymbol{A}-\boldsymbol{E}$. In this neuron, the onset of the calcium transient is out of phase with the ventral root burst onset. $\boldsymbol{K}$, Mean duration (and SD) of the cycle period (onset to onset) of ventral root bursts and calcium transients in seven neurons. $L$, The mean ratios of cycle duration of the calcium transients compared to the ventral root durations is close to $100 \%$ in all neurons, indicating a 1:1 ratio. $\boldsymbol{M}$, The mean onset of the calcium transients in each of the seven neurons is plotted in a polar plot, with $0^{\circ}$ representing the onset of the ventral root burst. $\boldsymbol{N}$, When these data are plotted in relation to the termination of the ventral root burst, the neuronal activity clusters into two groups, one with onset shortly after ventral root burst termination (first quadrant, as in the neuron depicted in $\boldsymbol{F}-\boldsymbol{J}$ ), and the second with onset before burst termination (as in the neuron in $\boldsymbol{A}-\boldsymbol{E}$ ). The arcs represent the mean frame capture duration.

or short propriospinal axons that project to motoneurons, DSCT neurons, and other lamina V/VI GAD65::GFP neurons. These neurons are rhythmically active during fictive locomotion and, based on the phase relationship of their activity to that of locomotor output, we suggest they form at least two physiologically distinct groups. We propose that these interneurons provide a source of rhythmic inhibitory input to extensor or flexor motoneurons during locomotion.

\section{Inhibitory interneurons in medial laminae V/VI}

As there are many physiologically distinct populations of inhibitory interneurons throughout the spinal cord, the GFP+ neurons in this GAD65::GFP transgenic line of mice are clearly a subset of GABAergic neurons. Given the coexpression of GAD isoforms in the spinal cord (Mackie et al., 2003), and the coexpression of GABA and glycine neurotransmitters (Todd and Sullivan, 1990), it was not surprising that GFP-expressing neurons also contained GAD67 or in rare instances GlyT2 in their terminals. By the same principles, it is possible that either the dorsally located GFP+ neurons in laminae I-II and/or laminae V/VI seen in these GAD65::GFP animals are the same as those expressing GFP in GAD67:GFP animals (Heinke et al., 2004; Dougherty et al., 2009).

The GFP + neurons in this study may be homologous to any of a number of inhibitory interneurons identified in the cat (Jankowska, 1992; Bannatyne et al., 2009). For example, they may be a subpopulation of interneurons receiving group II input (Jankowska, 1992). However, the group II inhibitory interneurons that project to motoneurons are in intermediate to ventral laminae, are primarily glycinergic, and do not project to Clarke's column. In the region where GFP+ neurons are located in these GAD65::GFP mice, medial laminae V/VI, there have been two prominent populations of inhibitory neurons previously identified: (1) those responsible for presynaptic inhibition of group Ia afferent synapses on motoneurons (Hughes et al., 2005) and (2) those responsible for nonreciprocal inhibition (Czarkowska et al., 1981; Jankowska et al., 1981; Brink et al., 1983).

The presynaptic inhibition of primary afferents in lamina IX is mediated by P-boutons (Conradi, 1969). As P-boutons are strongly GAD65 positive (Hughes et al., 2005), we expected to find their cells of origin in these animals. Interestingly, al- 
though the neurons are in a location similar to those supplying P-boutons (Hughes et al., 2005; Betley et al., 2009), the P-boutons in the transgenic line of GAD65::GFP mice used in this study do not express GFP. Hence, there are at least two distinct populations of GABAergic neurons in close proximity (or intermingled) in medial laminae V/VI: one involved in presynaptic inhibition of primary afferents, and the other involved in postsynaptic inhibition of motoneurons. The relationship between these populations of GABAergic interneurons is unknown at present.

As GFP+ boutons appose motoneuronal somata, at least some GFP + neurons may be classified as last-order interneurons. We cannot definitively determine whether these boutons arise from the GFP + interneurons located in laminae V/VI, dorsal laminae I-II, or descending neurons (Holstege, 1991). However, it is unlikely that inhibitory neurons in the superficial dorsal horn project directly to motoneurons (Heinke et al., 2004). Although axonal projections could not be completely reconstructed in the slice, fibers were observed originating from the region of medial laminae V/VI and coursing toward the motor pools. Thus, we propose that some lamina V/VI GFP+ neurons project to motoneurons, and hence are involved in the direct regulation of motoneuronal activity. However, dual patch-clamp recordings will be necessary to definitively establish connectivity (Wilson et al., 2007a).

Myelinated primary afferent terminals are immunoreactive for VGLUT1 (Todd et al., 2003; Hughes et al., 2005), and hence the presence of large VGLUT1 + boutons on somata of lamina $\mathrm{V} / \mathrm{VI}$ GFP + neurons indicates that some of these neurons may receive primary afferent input. Functional input was demonstrated by recording calcium transients using two-photon excitation imaging techniques (Wilson et al., 2007b), in response to low-threshold dorsal root stimulation. Together with possible projections to motoneurons, these results suggest that some GFP + GABAergic neurons in this region are involved in disynaptic inhibitory reflex pathways. In the cat, inhibitory interneurons in laminae V/VI responsible for nonreciprocal inhibition receive input from both group Ia and Ib primary afferents and project to and thus inhibit motoneurons (Czarkowska et al., 1981; Brink et al., 1983). As a population, these cat interneurons also inhibit other interneurons in laminae V/VI and inhibit Clarke's column neurons (Brink et al., 1983). We have demonstrated that mouse GFP+ GABAergic interneurons located in the same region as these cat interneurons have direct connections with motoneurons, DSCT, and other GABAergic interneurons and receive primary afferent input. However, there is one critical difference: nonreciprocal inhibition in the cat is mediated by glycine (Rudomin et al., 1990), and we found very little glyT2 expression in GFP + boutons in these mice. Therefore, although there are functional similarities, we cannot conclude that the GABAergic interneurons studied here are homologs of cat group I nonreciprocal inhibitory interneurons. That is, unless the transmitter phenotype differs between these two species, there are at least three distinct populations of inhibitory neurons located in this region of the spinal cord.

Bannatyne et al. (2009) have recently characterized inhibitory interneurons in the lumbar intermediate gray matter in the cat. They identified neurons that receive low-threshold muscle afferent input and project ipsilaterally, including to motor pools. Most of the inhibitory neurons were glycinergic; the GABAergic neurons were found to form $\mathrm{P}$-bouton synapses in contrast to our study. The degree of overlap in the populations reported in these two studies remains to be determined.
The number of distinct populations of GFP + neurons in medial laminae V/VI studied here is not clear. There are clear differences among the neurons, such as the presence of VGLUT1 boutons on only some somata, and the different phasing of the activity of these neurons during locomotion. In addition, it seems likely that their projection patterns to other GFP neurons in this region, to motoneurons, and to DSCT neurons differs between neurons [as is the case with nonreciprocal inhibitory neurons (Brink et al., 1983)].

\section{Possible contribution of GFP + medial lamina V/VI inhibitory interneurons to phasic inhibition of motoneurons} It has been known for many years that motoneurons receive alternating excitatory and inhibitory input during locomotion (Shefchyk and Jordan, 1985; Orsal et al., 1986). There is evidence that Ia inhibitory interneurons contribute to rhythmic motoneuron inhibition (Feldman and Orlovsky, 1975; Pratt and Jordan, 1987). However, these neurons derive from the V1 class of developing interneurons (Alvarez et al., 2005), and rhythmic inhibition of motoneurons remains after eliminating or silencing V1 interneurons (Gosgnach et al., 2006). One possible explanation is that some Ia inhibitory neurons may derive from other progenitor domains, and thus are not eliminated with these genetic techniques (Wang et al., 2008). Although rhythmic activity in itself only indicates input from locomotor networks, given the evidence of axonal projections to motoneurons, it is possible that the GABAergic neurons defined here comprise at least one source of the remaining rhythmic inhibitory input to motoneurons during locomotion.

It should be noted that the absence of particular disynaptic IPSPs recorded in motoneurons during locomotor activity (Angel et al., 2005) does not preclude the contribution of the interneuronal population mediating those IPSPs to the activity of motoneurons during locomotion. During locomotion in the cat, stimulation of low-threshold muscle afferents produces shortlatency excitation rather than inhibition of motoneurons (Conway et al., 1987; Gossard et al., 1994; McCrea et al., 1995; Angel et al., 1996). This is thought to result from locomotor network-related disinhibition of group I excitatory interneurons (Angel et al., 1996), possibly concurrent with tonic postsynaptic inhibition of group I nonreciprocal inhibitory interneurons (Angel et al., 2005). However, the lack of IPSPs recorded in motoneurons does not negate the possibility that inhibitory interneurons receiving group I input are rhythmically active during locomotion. Indeed, if these interneurons are involved in last-order inhibition during locomotion, and if the last order inhibitory interneurons to flexor and extensor motoneurons reciprocally inhibit each other [as in many models, e.g., Burke et al. (2001) and McCrea and Rybak (2008)], then one may not record group I afferent-evoked inhibition of motoneurons during locomotion. That is, during the flexor phase of the step cycle, the interneurons that inhibit extensor motoneurons would already be active (contributing to the inhibitory phase of extensor motoneurons), and IPSPs recorded in motoneurons would thus be occluded. During the extensor phase of the step cycle, the interneurons themselves would be inhibited (e.g., by interneurons inhibiting the flexor motoneurons), and thus no motoneuronal IPSP would be evoked. Thus, caution must be exercised in inferring interneuronal activity based on motoneuron activity. Determining whether or not a population of last-order inhibitory interneurons contributes to phasic inhibition of motoneurons requires direct recording from these interneurons during locomotion. In this study, we have demonstrated that two photon excitation imaging from an identified population of inhibitory interneurons is one method that can be used to accomplish such recordings. 
In summary, we have identified a population of inhibitory interneurons in medial laminae V/VI of the mouse spinal cord that are rhythmically active during locomotion. We have presented evidence that at least some of these interneurons are last order, and thus propose that their activity contributes to phasic inhibition of motoneurons and hence to the locomotor pattern.

\section{References}

Alvarez FJ, Jonas PC, Sapir T, Hartley R, Berrocal MC, Geiman EJ, Todd AJ, Goulding M (2005) Postnatal phenotype and localization of spinal cord V1 derived interneurons. J Comp Neurol 493:177-192.

Angel MJ, Guertin P, Jiménez I, McCrea DA (1996) Group I extensor afferents evoke disynaptic EPSPs in cat hindlimb extensor motorneurones during fictive locomotion. J Physiol 494:851-861.

Angel MJ, Jankowska E, McCrea DA (2005) Candidate interneurones mediating group I disynaptic EPSPs in extensor motoneurones during fictive locomotion in the cat. J Physiol 563:597-610.

Bannatyne BA, Liu TT, Hammar I, Stecina K, Jankowska E, Maxwell DJ (2009) Excitatory and inhibitory intermediate zone interneurons in pathways from feline group I and II afferents: differences in axonal projections and input. J Physiol 587:379-399.

Barber RP, Vaughn JE, Roberts E (1982) The cytoarchitecture of GABAergic neurons in rat spinal cord. Brain Res 238:305-328.

Betley JN, Wright CV, Kawaguchi Y, Erdélyi F, Szabó G, Jessell TM, Kaltschmidt JA (2009) Stringent specificity in the construction of a GABAergic presynaptic inhibitory circuit. Cell 139:161-174.

Brink E, Jankowska E, McCrea DA, Skoog B (1983) Inhibitory interactions between interneurones in reflex pathways from group Ia and group Ib afferents in the cat. J Physiol 343:361-373.

Burke RE, Degtyarenko AM, Simon ES (2001) Patterns of locomotor drive to motoneurons and last-order interneurons: clues to the structure of the CPG. J Neurophysiol 86:447-462.

Cabaj A, Stecina K, Jankowska E (2006) Same spinal interneurons mediate reflex actions of group Ib and group II afferents and crossed reticulospinal actions. J Neurophysiol 95:3911-3922.

ConradiS (1969) Ultrastructure of dorsal root boutons on lumbosacral motoneurons of the adult cat, as revealed by dorsal root section. Acta Physiol Scand Suppl 332:85-115.

Conway BA, Hultborn H, Kiehn O (1987) Proprioceptive input resets central locomotor rhythm in the spinal cat. Exp Brain Res 68:643-656.

Czarkowska J, Jankowska E, Sybirska E (1981) Common interneurones in reflex pathways from group $1 \mathrm{a}$ and $1 \mathrm{~b}$ afferents of knee flexors and extensors in the cat. J Physiol 310:367-380.

Dai X, Noga BR, Douglas JR, Jordan LM (2005) Localization of spinal neurons activated during locomotion using the $\mathrm{c}$-fos immunohistochemical method. J Neurophysiol 93:3442-3452.

Dougherty KJ, Sawchuk MA, Hochman S (2009) Phenotypic diversity and expression of GABAergic inhibitory interneurons during postnatal development in lumbar spinal cord of glutamic acid decarboxylase 67-green fluorescent protein mice. Neuroscience 163:909-919.

Dumoulin A, Lévi S, Riveau B, Gasnier B, Triller A (2000) Formation of mixed glycine and GABAergic synapses in cultured spinal cord neurons. Eur J Neurosci 12:3883-3892.

Esclapez M, Tillakaratne NJ, Kaufman DL, Tobin AJ, Houser CR (1994) Comparative localization of two forms of glutamic acid decarboxylase and their mRNAs in rat brain supports the concept of functional differences between the forms. J Neurosci 14:1834-1855.

Feldblum S, Erlander MG, Tobin AJ (1993) Different distributions of GAD65 and GAD67 mRNAs suggest that the two glutamate decarboxylases play distinctive functional roles. J Neurosci Res 34:689-706.

Feldman AG, Orlovsky GN (1975) Activity of interneurons mediating reciprocal la inhibition during locomotion. Brain Res 84:181-194.

Gong S, Zheng C, Doughty ML, Losos K, Didkovsky N, Schambra UB, Nowak NJ, Joyner A, Leblanc G, Hatten ME, Heintz N (2003) A gene expression atlas of the central nervous system based on bacterial artificial chromosomes. Nature 425:917-925.

Gosgnach S, Lanuza GM, Butt SJ, Saueressig H, Zhang Y, Velasquez T, Riethmacher D, Callaway EM, Kiehn O, Goulding M (2006) V1 spinal neurons regulate the speed of vertebrate locomotor outputs. Nature 440:215-219.

Gossard JP, Brownstone RM, Barajon I, Hultborn H (1994) Transmission in a locomotor-related group Ib pathway from hindlimb extensor muscles in the cat. Exp Brain Res 98:213-228.

Graham BA, Brichta AM, Callister RJ (2007) Moving from an averaged to specific view of spinal cord pain processing circuits. J Neurophysiol 98:1057-1063.

Hantman AW, van den Pol AN, Perl ER (2004) Morphological and physiological features of a set of spinal substantia gelatinosa neurons defined by green fluorescent protein expression. J Neurosci 24:836-842.

Heinke B, Ruscheweyh R, Forsthuber L, Wunderbaldinger G, Sandkühler J (2004) Physiological, neurochemical and morphological properties of a subgroup of GABAergic spinal lamina II neurones identified by expression of green fluorescent protein in mice. J Physiol 560:249-266.

Holstege JC (1991) Ultrastructural evidence for GABAergic brain stem projections to spinal motoneurons in the rat. J Neurosci 11:159-167.

Hongo T, Jankowska E, Ohno T, Sasaki S, Yamashita M, Yoshida K (1983a) The same interneurones mediate inhibition of dorsal spinocerebellar tract cells and lumbar motoneurones in the cat. J Physiol 342:161-180.

Hongo T, Jankowska E, Ohno T, Sasaki S, Yamashita M, Yoshida K (1983b) Inhibition of dorsal spinocerebellar tract cells by interneurones in upper and lower lumbar segments in the cat. J Physiol 342:145-159.

Hughes DI, Polgár E, Shehab SA, Todd AJ (2004) Peripheral axotomy induces depletion of the vesicular glutamate transporter VGLUT1 in central terminals of myelinated afferent fibres in the rat spinal cord. Brain Res 1017:69-76.

Hughes DI, Mackie M, Nagy GG, Riddell JS, Maxwell DJ, Szabó G, Erdélyi F, Veress G, Szucs P, Antal M, Todd AJ (2005) P boutons in lamina IX of the rodent spinal cord express high levels of glutamic acid decarboxylase- 65 and originate from cells in deep medial dorsal horn. Proc Natl Acad Sci USA 102:9038-9043.

Jankowska E (1992) Interneuronal relay in spinal pathways from proprioceptors. Prog Neurobiol 38:335-378.

Jankowska E, McCrea D, Mackel R (1981) Pattern of 'non-reciprocal' inhibition of motoneurones by impulses in group Ia muscle spindle afferents in the cat. J Physiol 316:393-409.

Jiang Z, Carlin KP, Brownstone RM (1999a) An in vitro functionally mature mouse spinal cord preparation for the study of spinal motor networks. Brain Res 816:493-499.

Jiang Z, Rempel J, Li J, Sawchuk MA, Carlin KP, Brownstone RM (1999b) Development of L-type calcium channels and a nifedipine-sensitive motor activity in the postnatal mouse spinal cord. Eur J Neurosci 11:3481-3487.

Jordan LM (1983) Factors determining motoneuron rhythmicity during fictive locomotion. Symp Soc Exp Biol 37:423-444.

Konkle AT, Bielajew C (2004) Tracing the neuroanatomical profiles of reward pathways with markers of neuronal activation. Rev Neurosci 15:383-414.

Kriellaars DJ, Brownstone RM, Noga BR, Jordan LM (1994) Mechanical entrainment of fictive locomotion in the decerebrate cat. J Neurophysiol 71:2074-2086.

Lanuza GM, Gosgnach S, Pierani A, Jessell TM, Goulding M (2004) Genetic identification of spinal interneurons that coordinate left-right locomotor activity necessary for walking movements. Neuron 42:375-386.

Lao L, Marvizón JC (2005) GABA(A) receptor facilitation of neurokinin release from primary afferent terminals in the rat spinal cord. Neuroscience 130:1013-1027.

Le Bars D (2002) The whole body receptive field of dorsal horn multireceptive neurones. Brain Res Brain Res Rev 40:29-44.

Mackie M, Hughes DI, Maxwell DJ, Tillakaratne NJ, Todd AJ (2003) Distribution and colocalisation of glutamate decarboxylase isoforms in the rat spinal cord. Neuroscience 119:461-472.

McCrea DA, Rybak IA (2008) Organization of mammalian locomotor rhythm and pattern generation. Brain Res Rev 57:134-146.

McCrea DA, Pratt CA, Jordan LM (1980) Renshaw cell activity and recurrent effects on motoneurons during fictive locomotion. J Neurophysiol 44:475-488.

McCrea DA, Shefchyk SJ, Stephens MJ, Pearson KG (1995) Disynaptic group I excitation of synergist ankle extensor motoneurones during fictive locomotion in the cat. J Physiol 487:527-539.

McLaughlin BJ, Barber R, Saito K, Roberts E, Wu JY (1975) Immunocytochemical localization of glutamate decarboxylase in rat spinal cord. J Comp Neurol 164:305-321.

Nakayama K, Nishimaru H, Kudo N (2002) Basis of changes in left-right 
coordination of rhythmic motor activity during development in the rat spinal cord. J Neurosci 22:10388-10398.

Orsal D, Perret C, Cabelguen JM (1986) Evidence of rhythmic inhibitory synaptic influences in hindlimb motoneurons during fictive locomotion in the thalamic cat. Exp Brain Res 64:217-224.

Perret C (1983) Centrally generated pattern of motoneuron activity during locomotion in the cat. Symp Soc Exp Biol 37:405-422.

Pratt CA, Jordan LM (1987) Ia inhibitory interneurons and Renshaw cells as contributors to the spinal mechanisms of fictive locomotion. J Neurophysiol 57:56-71.

Quinlan KA, Kiehn O (2007) Segmental, synaptic actions of commissural interneurons in the mouse spinal cord. J Neurosci 27:6521-6530.

Rudomin P, Schmidt RF (1999) Presynaptic inhibition in the vertebrate spinal cord revisited. Exp Brain Res 129:1-37.

Rudomin P, Solodkin M, Jiménez I (1987) Synaptic potentials of primary afferent fibers and motoneurons evoked by single intermediate nucleus interneurons in the cat spinal cord. J Neurophysiol 57:1288-1313.

Rudomin P, Jiménez I, Quevedo J, Solodkin M (1990) Pharmacologic analysis of inhibition produced by last-order intermediate nucleus interneurons mediating nonreciprocal inhibition of motoneurons in cat spinal cord. J Neurophysiol 63:147-160.

Shefchyk S, McCrea D, Kriellaars D, Fortier P, Jordan L (1990) Activity of interneurons within the L4 spinal segment of the cat during brainstemevoked fictive locomotion. Exp Brain Res 80:290-295.

Shefchyk SJ, Jordan LM (1985) Motoneuron input-resistance changes during fictive locomotion produced by stimulation of the mesencephalic locomotor region. J Neurophysiol 54:1101-1108.

Soghomonian JJ, Martin DL (1998) Two isoforms of glutamate decarboxylase: why? Trends Pharmacol Sci 19:500-505.

Stosiek C, Garaschuk O, Holthoff K, Konnerth A (2003) In vivo two-photon calcium imaging of neuronal networks. Proc Natl Acad Sci U S A 100:7319-7324
Szûcs P, Odeh F, Szokol K, Antal M (2003) Neurons with distinctive firing patterns, morphology and distribution in laminae V-VII of the neonatal rat lumbar spinal cord. Eur J Neurosci 17:537-544.

Theiss RD, Heckman CJ (2005) Systematic variation in effects of serotonin and norepinephrine on repetitive firing properties of ventral horn neurons. Neuroscience 134:803-815.

Todd AJ, Sullivan AC (1990) Light microscope study of the coexistence of GABA-like and glycine-like immunoreactivities in the spinal cord of the rat. J Comp Neurol 296:496-505.

Todd AJ, Hughes DI, Polgár E, Nagy GG, Mackie M, Ottersen OP, Maxwell DJ (2003) The expression of vesicular glutamate transporters VGLUT1 and VGLUT2 in neurochemically defined axonal populations in the rat spinal cord with emphasis on the dorsal horn. Eur J Neurosci 17:13-27.

Walmsley B (1991) Central synaptic transmission: studies at the connection between primary afferent fibres and dorsal spinocerebellar tract (DSCT) neurones in Clarke's column of the spinal cord. Prog Neurobiol 36:391-423.

Wang Z, Li L, Goulding M, Frank E (2008) Early postnatal development of reciprocal Ia inhibition in the murine spinal cord. J Neurophysiol 100:185-196.

Wilson JM, Hartley R, Maxwell DJ, Todd AJ, Lieberam I, Kaltschmidt JA, Yoshida Y, Jessell TM, Brownstone RM (2005) Conditional rhythmicity of ventral spinal interneurons defined by expression of the Hb9 homeodomain protein. J Neurosci 25:5710-5719.

Wilson JM, Cowan AI, Brownstone RM (2007a) Heterogeneous electrotonic coupling and synchronization of rhythmic bursting activity in mouse hb9 interneurons. J Neurophysiol 98:2370-2381.

Wilson JM, Dombeck DA, Díaz-Ríos M, Harris-Warrick RM, Brownstone RM (2007b) Two-photon calcium imaging of network activity in XFPexpressing neurons in the mouse. J Neurophysiol 97:3118-3125.

Yoshimura M, Nishi S (1995) Primary afferent-evoked glycine- and GABAmediated IPSPs in substantia gelatinosa neurones in the rat spinal cord in vitro. J Physiol 482:29-38. 